\title{
Autoimmune/inflammatory syndrome induced by adjuvants - a new diagnostic problem or the solution of a diagnostic riddle
}

\author{
Autoimmunologiczny/autozapalny zespót indukowany przez adiuwanty - nowy \\ problem diagnostyczny czy rozwiązanie zagadki diagnostycznej
}

\begin{abstract}
Maria Maślińska1, Carlo Perricone², Yehuda Shoenfeld ${ }^{3,4}$
1Early Arthritis Clinic, Institute of Rheumatology Warsaw, Poland

2Dipartimento di Medicina Interna e Specialità Mediche, Sapienza Università di Roma, Italy

${ }^{3}$ The Zabludowicz Centre of Autoimmune Diseases, Sheba Medical Centre, Tel-Hashomer, Israel

4 Incumbent of the Laura Schwarz-Kipp Chair for Research of Autoimmune Diseases, Tel-Aviv University, Israel

${ }^{1}$ Klinika Wczesnego Zapalenia Stawów, Instytut Reumatologii im. prof. dr hab. med. Eleonory Reicher w Warszawie

2Klinika Medycyny Wewnętrznej i Specjalistycznej, Sapienza - Uniwersytet Rzymski we Włoszech

${ }^{3}$ Centrum Chorób Autoimmunologicznych im. Zabludowicza, Centrum Medyczne Sheba, Tel-Hashomer w Izraelu

4Pełniący obowiązki kierownika ds. Badań nad Chorobami Immunologicznymi, Uniwersytet Tel Awiwu w Izraelu
\end{abstract}

Key words: adjuvants, immune response, autoimmune diseases.

Słowa kluczowe: adiuwanty, odpowiedź immunologiczna, choroby autoimmunologiczne.

\section{Sum mary}

Autoimmune/inflammatory syndrome induced by adjuvants (ASIA) is a newly identified syndrome dealing with pathological effects of adjuvant use. In recent years observations have shown that a number of clinical situations displaying similar features can be associated with an overactive immune response and with the inflammatory effect of adjuvants administration. Chronic stimulation of the immune system by substances used as adjuvants may lead to the occurrence of numerous symptoms such as chronic fatigue, arthritis, myalgia, cognitive impairment and neurological disorders. The aim of this article is to present how and why adjuvants - while allegedly causing no specific immune response - may become a cause of development of autoimmune diseases.

\section{Introduction}

The word "adjuvant" derives from the Latin word "adiuvare" - "to help". The search for adjuvants - or substances that enhance the ability of the antigen to elicit an immune response while showing no antigenic properties themselves - started with the development of vaccinology. Adjuvants

\section{Streszczenie}

Autoimmunologiczny/autozapalny zespót indukowany przez adiuwanty (ASIA) jest nowo zdefiniowanym zespołem powiązanym z niepożądanym skutkiem zastosowania adiuwantów. Obserwacje ostatnich lat wykazały, że podobne sytuacje kliniczne mogą być związane z hiperreaktywnością odpowiedzi immunologicznej oraz prozapalnym działaniem zastosowanych adiuwantów. Przewlekła stymulacja układu immunologicznego przez substancje stosowane jako adiuwanty może prowadzić do wystąpienia licznych objawów, takich jak: przewlekłe zmęczenie, zapalenie stawów, bóle mięśni, pogorszenie zdolności poznawczych czy zaburzenia neurologiczne. Celem niniejszego artykułu jest przedstawienie, w jaki sposób i dlaczego adiuwanty - mimo iż mają być pozbawione specyficznego wpływu na odpowiedź immunologiczną - mogą się stać przyczyną rozwoju chorób autoimmunologicznych.

intensify the humoral and cellular immune response. The use of adjuvants allows the reduction of the antigen dose in the vaccine or even the vaccines frequency, inhibits the reactions between antigens in polyvalent vaccines and stimulates an immune response in individuals with impaired reaction to vaccination.

Address for correspondence:

Maria Maślińska, Instytut Reumatologii im. prof. dr hab. med. Eleonory Reicher, ul. Spartańska 1, 02-637 Warszawa,

e-mail: maslinskam@gmail.com

Submitted: 10.10.2013 
The first discovered adjuvant was Freund's complete adjuvant - a mixture of paraffin oil and mycobacterium antigen - CFA (complete Freund's adjuvant). Together with its next variation - IFA (incomplete Freund's adjuvant), devoid of Mycobacterium tuberculosis antigen - it is still in use in research. Complete Freund's adjuvant slows the release of the antigen and acts through Toll-like receptors (TLR), which recognize mycobacterial antigen, leading to activation and proliferation of $T$ cells, in particular by means of Th1 activation and advantages of the cellular response. However, CFA proved to be too toxic to humans, so its use on a large scale was impossible. Yet, it is still used in animal models. Incomplete Freund's adjuvant stimulates the Th2 pathway of immunological response, leading to the development of humoral immunity [1, 2]. Aluminum (Al) has been used as an adjuvant since 1926 in many vaccines (with the exception of live attenuated vaccines), as it prolongs the time antigen remains in the place of the injection ("depot effect"), acts as an irritant at the injection site, inducing local immune reactions, and activates the complement system. Al promotes the Th2 response, whereas in the presence of other adjuvants such as cellular wall lipopolysaccharides (LPS), non-methylated dinucleotide sequences (CpG) or extrinsic interleukin (IL)-18, Al promotes the Th1 response [3]. Among the inorganic compounds, calcium phosphate is presently used as an adjuvant, while beryllium hydroxide is still undergoing trials [2]. As organic adjuvants, cellular wall elements such as LPS and lipid A and its weaker pyrogenic form monophosphoryl lipid $\mathrm{A}(\mathrm{MPL})$ are used (the latter in combination with an Al salt as the SBAS4 adjuvant system in vaccines against hepatitis B).

Other examples of organic adjuvants are synthetic analogues of muramyl dipeptide (MDP) - itself a highly pyrogenic derivative of the Mycobacterium cellular wall - which proved to work as an adjuvant in humans. The nonmethylated dinucleotide sequences derived from bacterial DNA (CpG) are used as adjuvants as well. They are recognized by the TLR-9 receptor, which leads to polyclonal B cell activation and antibody production. Additionally the $C P G$ sequence is recognized by antigen-presenting cells (APC), resulting in cytokine secretion - mainly of the proinflammatory kind (e.g. interferons, IL-6, IL-12, IL-18, TNF- $\alpha$ ), but also of IL-10. This pathway drives the immune response towards Th1 and stimulation of cellmediated immunity. A notable group of natural adjuvants of practical importance - in particular for the mucosal response associated with stimulation of the synthesis of specific IgA antibodies - is the enterotoxins: cholera toxin (CT) and Escherichia coli enterotoxin (LT). Enterotoxins affect antigen-presenting cells, stimulate the expression of MHC $\|$, costimulatory molecules, chemokines and IL-1.
Another bacterial toxin finding use as an adjuvant in the vaccines is a diphtheria toxoid. Artificial substances are as useful as adjuvants, particularly Syntex adjuvant formulation (SAF), containing a lipid compound - squalene (synthetic cholesterol precursor), a synthetic derivative of MDP and detergent (Tween 20). There are attempts to use this adjuvant in a vaccine against human immunodeficiency virus. Water emulsions of squalene (MF 59 stabilized with Tween 80 and Span 85 detergents) are commonly used within influenza, HBV, HSV and CMV vaccines [1, 2, 4, 5].

In 1994 the concept of virosomes was presented. They were initially introduced in the hepatitis A vaccine, but were soon applied in the influenza vaccines. The virosomes consist of liposomes - spherical formations with a lipid membrane - to which inner aqueous phase antigens are introduced. The structure of the liposome may be varied and adapted to different antigens, including bacterial. In the case of flu vaccine IRIV (immunopotentiating reconstituted influenza virosome) influenza virus proteins (hemagglutinin and neuraminidase) have been integrated with the lipid membrane glycoproteins $[4,5]$. Currently, research is being carried out into the utilization of polymers as adjuvants with polymers acting as antigen "carriers" and thus retarding its release. This leads to increased antigen presentation, achieved through various processes: TLR activation, direct phagocytosis, nucleosome path activation (secretion of IL-1 $\beta$ ) and antigen presentation by APCs to naive T cells, using major histocompatibility complex (MHC) antigens. The B lymphocytes (recalling the $B C R)$ are also directly affected.

Natural polymers exploited as adjuvants include derivatives of polysaccharides such as dextran, lentinan, inulin, mannose, chitosan and PGA (poly- $\gamma$-glutamic acid) polypeptide.

Synthetic polymers (micro- and nanoparticles) can be directly internalized by the lymphatic system and remain there for a long time, stimulating the immune system, while allowing the use of a decreased antigen dose. The synthetic polymers comprise multiphase emulsions such as Tween 80 (polyoxyethylene sorbitan monooleate); polyphosphazenes such as poly[di(sodium carboxylatophenoxy) phosphazene] (PCEP), used with X31 influenza virus antigen; polyelectrolytes, as a polyelectrolyte multilayer capsule (PMLC); polyanhydrides acquired through dehydration of acids or mixtures thereof; and many other substances (nonionic block copolymers, polymethacrylates, polycaprolactones, polyglycolic-co-lactides, polyvinylpyrrolidone, cationic polymers) [6]. Research is also aimed at finding a substance which will selectively activate B and T lymphocytes or macrophages, thus raising interest in cytokines such as granulocytes macrophage-colony stimulating factor (GM-CSF), IL-1, IL-2, IL-12 or interferon $\gamma($ IFN- $\gamma$ ) as potential adjuvants (Fig. 1). 


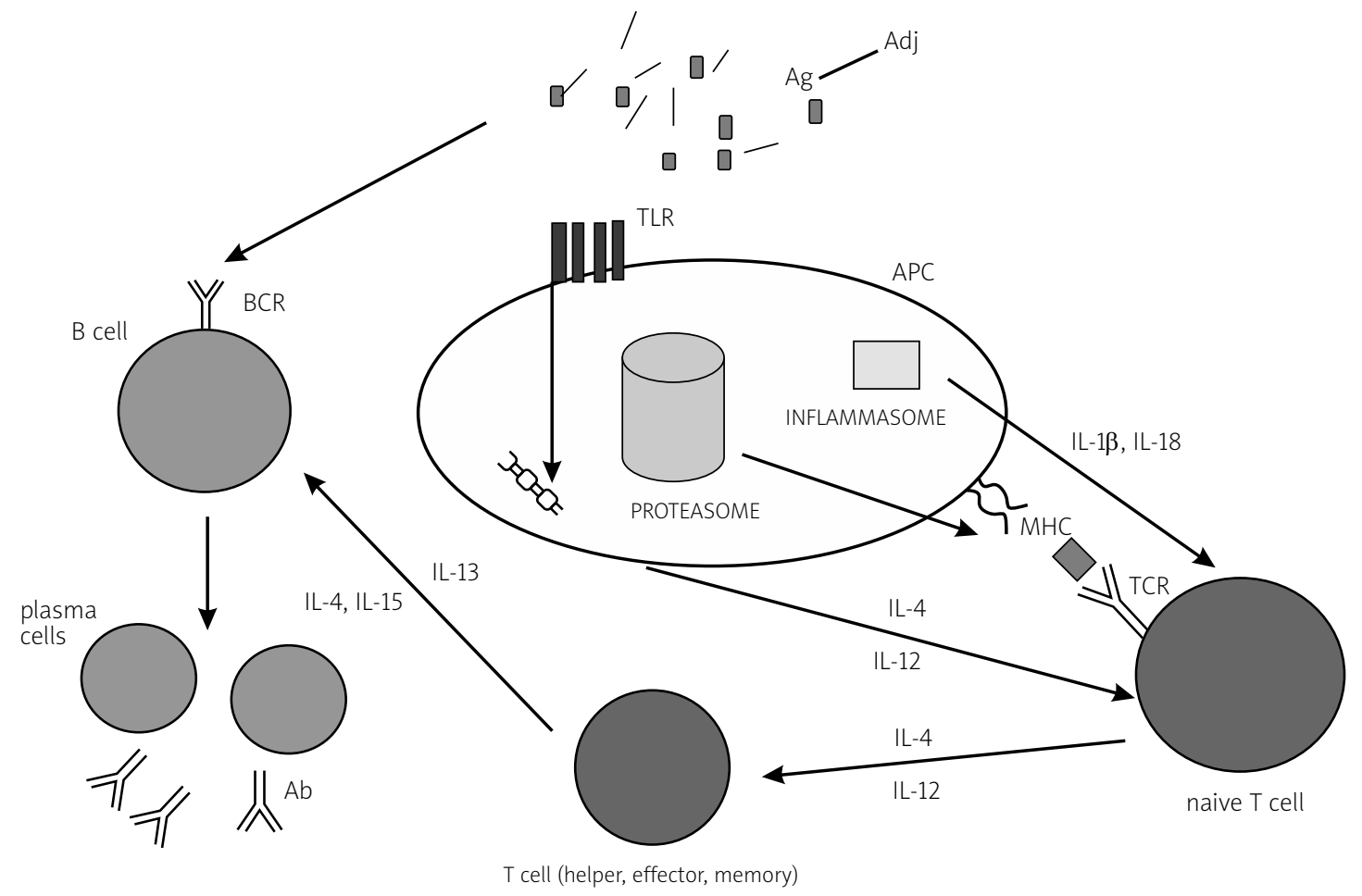

$A P C$ - antigen presenting cel, Ag - antigen, Adj-adjuvant, Ab - antibody, TLRs - toll-like receptors, TCR - T cell receptor, BCR $B$ cell receptor, IL - interleukin, $M H C$ - major histocompatibility complex, inflammasome - multiproteine oligomer which promotes maturation IL $1 \beta$ and IL 18 (inflammatory cytokines), proteasome - multicatalytic protease that degrades polyubiquitinated proteins to small peptides

Fig. 1. Possible ways of action of adjuvants

\section{Autoimmune/inflammatory syndromes induced by adjuvants}

The interconnections between adjuvant use and autoimmunity are being currently recognized and ASIA (autoimmune/inflammatory syndrome induced by adjuvants) is a recently identified syndrome defined in the wake of recognition of a link between use of adjuvants and activation of the autoimmune process. The introduction of ASIA merges in one nosological entity post-adjuvant emergency of a number of symptoms previously attributed to specific autoimmune diseases, e.g. systemic lupus erythematosus (SLE), systemic sclerosis (SSc) and rheumatoid arthritis (RA). The current list of conditions considered to be part of ASIA syndrome includes post-vaccination phenomena, siliconosis as a result of silicone breast implant operations (SBI), Gulf War syndrome (GWS) and macrophagic myofasciitis (MMF) [7].

In 2011, the criteria to diagnose ASIA were proposed [7]. Among the major criteria exposure to external stimuli (infection, vaccination, silicon and other adjuvant) prior to clinical manifestations was listed. The following symptoms were established as the main "typical" clinical manifestations: myalgia, myositis and muscle weakness, arthralgia and/or arthritis as well as chronic fatigue, unrefreshing sleep or sleep disturbances and neurological manifestations (especially associated with demyelination) or cognitive impairment and memory loss. Last but not least, pyrexia and mouth dryness can be listed among typical manifestations.

Improvement after removal of the factor associated with occurrence of the symptoms was presented as the third major criterion.

It should be noted that in many cases the information about possible vaccination or exposure to the above-mentioned factors/circumstances is not fully taken into account during the interview with patients, especially adult ones.

Such discrete symptoms as memory impairment, fatigue or unrefreshing sleep are not considered to be symptoms of the disease. In addition, it is often not possible to eliminate the causative factor (e.g. vaccine). Among listed clinical symptoms are those that may suggest the existence of autoimmune disease especially when we can confirm the picture of the disease in histological findings, after 
biopsy of involved organs, which is the fourth major criterion, or when we can confirm the presence of autoantibodies and antibodies directed against a suspected adjuvant (e.g. anti-silicone antibodies, anti-squalene antibodies) $[8,9]$.

The minor criteria for the diagnosis of ASIA syndrome further include the presence of antibodies/autoantibodies, specific HLA (i.e. HLA-DRB1, HLA-DQB1), clinical manifestations such as irritable bowel syndrome, as well as the evolution of the picture of the disease towards the determined autoimmune disease (SLE, SSc, RA, MS).

\section{Post-vaccination phenomena}

Vaccinology has its beginnings in the eighteenth century, when Mary Wortley Montagu, an English aristocrat, presented in London "variolation" - a method used to protect against smallpox in the Ottoman Empire, observed by Lady Montagu during her stay in Constantinople. In variolation the patient was inoculated with the live virus acquired from blisters of infected individuals; therefore the procedure presented a risk of infection, and some of the immunized persons developed smallpox. Later on, Edward Jenner developed a safer smallpox vaccine based on bovine virus (cowpox) instead of smallpox. Vaccination freed humanity from the threat of several widespread epidemics and limited the number of serious complications of many diseases. Nonetheless, over many years of vaccination case reports surfaced of conditions such as arthritis, Guillain-Barré syndrome, meningitis, chronic fatigue syndrome and vasculitis, being associated with a history of vaccination. In the case of Guillain-Barré syndrome, it has been reported that it developed after vaccination against the virus of "swine flu", as well as after antimeningococcal vaccine (Menactra - Sanofi Pasteur, Lyon, France) [10]. Arthritis has been reported after vaccination with diphtheria-tetanus-pertussis (DTP), while transverse myelitis has been reported after oral polio vaccination.

Table I. Clinical manifestations after HBV vaccination (acc. to [15])

\begin{tabular}{|lc|}
\hline Clinical manifestation & Percentage (\%) \\
\hline neuro-psychiatric & 70 \\
\hline musculoskeletal & 59 \\
\hline general symptoms & 60 \\
\hline gastrointestinal & 50 \\
\hline ophthalmic & 32 \\
\hline mucocutaneous & 30 \\
\hline local reactions & 10 \\
\hline
\end{tabular}

Autoimmune thrombocytopenia was observed after vaccination with measles-mumps-rubella (MMR) [11].

Complications after adjuvant administration were also the subject of research performed on animals, which revealed the rise of various autoantibodies in such cases, including those associated with SLE [12] antibodies to $\beta 2$ glycoprotein I ( $\beta 2 \mathrm{GPI})$, and anti-ferritin antibodies. Granulomatous disease of peritoneum and liver, glomerulonephritis and thromboembolic complications were also observed [13], as well as induced arthritis [14]. In a retrospective work by Zafrir et al. the analysis was performed on patients from various centers in the United States who developed symptoms of autoimmune diseases after hepatitis B vaccination. Notably the vaccine contained Al [15].

Altogether, 93 patients were assessed, mainly women (69.2\%). The average time from vaccination (last dose of the vaccine) to the onset of symptoms ranged from just a few days to up to 2 years. The most common manifestations described in this analysis are shown in Table I.

From a group of 93 patients, a cohort of 49 was serologically evaluated and $80 \%$ showed the presence of autoantibodies (Table II).

Among the cases in this analysis that did not fulfill the ASIA criteria, children were the most frequent and in 9 cases type 1 diabetes (T1D) was diagnosed. This evidence

Table II. Presence of autoantibodies following hepatitis $B$ vaccination (acc. to [15])

\begin{tabular}{|ll|}
\hline Autoantibodies & Percentage (\%) \\
\hline ANA & 57 \\
\hline RF & 28 \\
\hline anti-smooth muscle & 16 \\
\hline immune complex & 8 \\
\hline anti-dsDNA & 8 \\
\hline anti-RNP & 6 \\
\hline anti-Smith & 2 \\
\hline anti-SS A/Ro & 4 \\
\hline anti-SS B/La & 4 \\
\hline anti-myelin basic protein & 8 \\
\hline adrenal autoantibodies & 2 \\
\hline anti-cardiolipin & 4 \\
\hline anti-thyroglobulin & 2 \\
\hline anti-thyroid peroxidase & 8 \\
\hline anti-mitochondrial antibodies & 8 \\
\hline
\end{tabular}


requires further research and analysis of the relationship between immunization and the development of T1D [15]. Among 20 patients with the diagnosis of giant cell arteritis (GCA) and polymyalgia rheumatica (PMR) who were assessed in the work presented by Soriano et al. [16], 10 underwent flu vaccination 20 days to 3 months prior to the diagnosis of GCA/PMR. Also, the presence of HLA-DRB1 has been noted in patients who developed post-vaccination symptoms of GCA/PMR; therefore the authors suggested the impact of genetic predisposition to the disease after flu vaccination [16].

Al is being analyzed as a potential factor inducing the development of Crohn's disease (CD) - a chronic inflammatory bowel disease, leading to malnutrition, impaired immunity and potentially requiring treatment with steroids, immunosuppressants and biological agents. These features of CD contribute to the development of infection and confirm the need of vaccination in this group of patients. It is suggested that the link between the development of CD and the exposure to Al or use of other adjuvants requires further research [17]. One of the less acknowledged adjuvants - present in many vaccines, e.g. against hepatitis $B$ and $A$, due to the process of their production - is Saccharomyces cerevisiae or yeast, widely used in everyday baking and in the brewing industry. The anti-Saccharomyces cerevisiae antibodies (ASCAs) are directed against phosphopeptidomannan. Their presence is specific for $C D$, but they were also found in patients with other autoimmune diseases such as antiphospholipid syndrome (APS), SLE, RA and T1D. This leads to the conclusion that Saccharomyces - a commensal microorganism - in the presence of certain conditions, such as impaired immune tolerance, can trigger autoimmunity[18].

Moreover, CpG used as an adjuvant and its interaction with heat shock proteins and vasoactive neuropeptides may be linked to the development of fatigue-related autoimmune conditions $[19,20]$. Attention was paid to the development of symptoms of fatigue allowing the diagnosis of chronic fatigue syndrome (CFS) and, in some cases, also fibromyalgia (FB) in individuals after vaccination for hepatitis $B$. Therefore it can be assumed that in susceptible individuals HBV vaccine may trigger an autoimmune phenomena and CFS or FB symptoms [20].

\section{Adjuvants and anticardiolipin antibodies}

Anticardiolipin antibodies $(\mathrm{aCL})$ may be present in SLE, while the presence of $\mathrm{aCL}$ and lupus anticoagulant associated with clinical symptoms of thrombosis or obstetrical complications are the basis for the diagnosis of antiphospholipid syndrome (APS) [21]. aCL may be found in healthy individuals, but then their presence represents a risk factor for APS development. In the current revised
APS criteria, the presence of anti- $\beta 2$-glycoprotein antibodies has also been included, as they significantly increase the risk of thrombosis. It was demonstrated that vaccination and the use of an adjuvant may result in the appearance of autoantibodies including aCL Vista et al. [21] have shown that vaccination can stimulate antiphospholipid antibody (aPL) formation in patients with SLE and in healthy individuals and there was no statistically significant difference between these two groups. It has also been shown that $\mathrm{aCL}$ may arise in SLE patients but without associated appearance of anti- $\beta 2 \mathrm{GPI}$ antibodies. Indeed, no clinical features of APS were observed. In another work, Tarjan et al. [22] showed that SLE patients with aPL vaccinated against influenza may show a remarkable increase in anti- $\beta 2 \mathrm{GPI}$ antibody levels without any clinical consequences. This may suggest that the increase in the concentration of aCL antibodies and the de novo emergence of aCL were transient [22, 23].

Immunization of genetically susceptible heterozygous factor $V$ Leiden (FVL) mice with CFA and IFA showed the induction of specific autoantibodies ( $\beta 2 \mathrm{GPI}$-dependent), with the CFA immunized mice exhibiting hyperactive behavior correlated with the concentration of antibodies [23]. The authors hypothesized that in addition to adjuvant stimulation, and regardless of adjuvant type (CFA or IFA), the existing coagulation defect (thrombophilia) may predispose to autoimmunization development.

The issue of consequences of anti-human papilloma virus (HPV) vaccination has been brought up by Soldevilla et al. [24], who reported 3 patients developing de novo SLE or SLE exacerbation in a relatively short time (2-4 months) after immunization with the vaccine. Yet, SLE patients are at higher risk of developing cervical cancer, especially in case of immunosuppressive therapy; thus, the use of the anti-HPV vaccine has to be considered in this group. Although the study showed overall safety and effectiveness of the vaccine in SLE patients, it seems necessary to avoid immunization during the active stage of SLE and to pay additional attention to the possible development of autoimmunization after administering the vaccine [24, 25].

\section{Gulf War syndrome}

Chronic multi-symptom illness (CMI) develops after exposure to adjuvants. It is known that soldiers and military personnel before leaving for an overseas mission receive in a short period of time numerous vaccinations and they also have pyridostigmine bromide (PB) - a substance used in prophylaxis of nerve gas exposure-administered. Moreover, the everyday use of repellents, such as N,Ndiethyl-3-methylbenzamide (DEET), occurs. Servicemen and soldiers are also exposed to pesticides such as Lindane, Permethrin and phosphoorganic compounds, smoke from 
burning oil fields, depleted uranium used in ammunition and other chemicals used during military operations.

In 2008, the Research Advisory Committee on Gulf War Veterans' IIInesses found evidence linking exposure to PB with CMI development. However, in 2010 the Institute of Medicine (IOM) in the Gulf War and Health Report (update 2009) did not fully agree with this conclusion $[26,27]$. Gulf War syndrome (GWS) patients suffer mainly from fatigue, sleep disturbances, cognitive functions impairment, muscle pain and weakness, ataxia, excessive sweating, headache, fever, arthralgia, diarrhea, bladder dysfunction [symptoms similar to the clinical picture of chronic fatigue syndrome (CFS)], fibromyalgia (FB), irritable bowel syndrome (IBS), sick building syndrome and post-traumatic stress disorder. Apart from the above-described symptoms, a higher incidence of amyotrophic lateral sclerosis (ALS) has been noted, which is considered to be associated with the exposure to $\mathrm{PB}$ and $\mathrm{Al}[8,28]$.

\section{Macrophagic myofasciitis}

This syndrome was described by Gherardi et al. in 1998. Macrophagic myofasciitis (MMF) is caused by the deposition of Al in muscles. Al induces general symptoms, such as muscle pain, arthritis, muscle weakness, chronic fatigue, and fever, and may cause the development of demyelinating diseases (MS-like demyelinating disorders). Patients complain of memory and cognitive function impairment, difficulties in maintaining emotions and mood swings. A significant portion of patients with MMF meet the diagnostic criteria for CFS. In patients with a positive history of intramuscular injection of vaccine containing Al and suspected of MMF, muscle biopsy should be considered $[29,30]$.

Laboratory tests may show elevated creatine kinase (CK) levels, increased sedimentation rate, and the emergence of autoantibodies. Patients with MMF were described to have no other excessive exposure to Al compounds than vaccination (HBV, HAV, TT) and showed no features of kidney damage. In electromyography of MMF patients, primary muscle damage can be revealed. Al hydroxide deposits are locally visible in electron microscopy. Muscle biopsy reveals infiltration by PAS-positive $\mathrm{MHC}$ I positive macrophages and CD8+ T lymphocytes, without any signs of damage to the muscle fibers. The syndrome develops mainly in patients with HLA-DR B1*01. Subcutaneous immunization is not observed in MMF, but a vaccine containing Al as an adjuvant may cause chronic skin changes known as pseudo-lymphoma associated with macrophages containing an Al rim [31]. Gallium scintigraphy in patients with MMF shows radioisotope accumulation mainly in the region affected by pain, especially in the lower limbs fascias and periarticular tissues [32, 33].

\section{Silicone breast implants - siliconosis}

The first breast implant surgery with silicone gel (Cronin-Gerow implants) was performed in 1962. Eventually, three types of silicone implants were developed and are now in use. In these implants the silicone shell is filled with salt, silica gel or a mixture of substances (soybean oil, polypropylene, etc.). In the process of implant preparation it is necessary to use platinum as a catalyst for the transformation of silicone oil into gel. The presence of platinum in the tissue surrounding the implant has been reported. Platinum can be deposited in the bone and penetrate the nerve endings causing a disease of the nervous system. In currently used implants the amount of platinum is negligible and no significant risk of exposure to its toxicity is reported [34, 35]. Among the complications associated with the use of silicone breast implants, the most common is damage related to surgical technique, physical or chemical trauma. Contraction of the silicone coating, leakage of implant contents into the tissue and infection can also take place, as well as the development of an allergic reaction to both silicon and platinum [34, 35].

In women with silicone gel leakage FB has been described, as well as a variety of symptoms such as body aches, fatigue, cognitive impairment, depression, dry eyes and mouth, skin changes, paresthesia, swelling and pain of the salivary glands, unexplained fevers, hair loss, headaches and morning stiffness. Women after SBI have also been diagnosed with autoimmune diseases such as SLE, RA, scleroderma, and Sjögren's syndrome. In 1996, in a survey of 1,800 breast implant recipients, Hennekens et al. assessed at $1.25(95 \% \mathrm{Cl}: 1.08-1.41)$ the relative risk of the occurrence of immune diseases [36].

In 2000, Janowski et al. in their meta-analysis identified the risk of developing autoimmune disease as 0.8 [37]. Cases of adult onset Still's disease (AOSD) after breast implantation have also been reported. In an article by Jara et al. a case of lupus-like syndrome development and of life-threatening Still's disease reactivation was reported [38]. In this paper five other AOSD cases after SBI, described previously in the literature, were analyzed. Jara et al. reported that among all six discussed cases of AOSD after SBI, in two cases in which implants were not removed disseminated coagulopathy syndrome developed [38]. In patients with an autoimmune response after SBI, anti-silicone antibodies were found and IgG levels in the tissue surrounding the implant were elevated [9]. It has been noted that the risk of development of morphea type or scleroderma-like skin lesions or of eosinophilic fasciitis occurrence arises after SBI. It is explained by the silicone's influence of fibroblast proliferation and collagen production [39, 40].

The desire to improve the body is not limited to the use of breast implants, but also includes injections of many 
chemical substances for cosmetic purposes (such as mineral oil, guaiacol, liquid silicone, collagen, iodine gadital, paraffin), which carries the risk of not only infectious complications or cancer development, but also of autoimmune disease occurrence. In an interesting article by Vera Lastra et al. cases of undefined (60\% of cases) and defined autoimmune diseases (40\%) following injection of various illegal substances in Mexico City were analyzed. Histopathological evaluation of the injection site revealed the presence of granulomas, chronic inflammation, features of vasculitis, fibrosis and vacuoles filled with oil. Additionally, in the study group (50 cases), 4 (8\%) deaths associated with the investigated injections were reported during a 4-year follow-up [41].

\section{Discussion}

The basic problems arising from the present state of ASIA syndrome research concern the issues of associating the onset of ASIA symptoms with the history of adjuvant use and the time span between vaccination and the emergence of autoimmune disease. It is known that the rise of autoantibodies may precede disease symptoms by years. Symptoms may occur immediately after inoculation (as in the case of transverse myelitis) as well as a number of years later [42].

Polyvalent features of the vaccines may also have an influence on the occurrence of symptoms, but it is possible that it can be either attributed to the used adjuvants or to the "mixture" of antigens in the vaccine. The occurrence of autoimmune disorders after vaccination is relatively rare, considering the massive numbers of performed vaccinations. As in the case of the development of autoimmune disease, certain conditions must be met at the same time, such as exposure to an adjuvant, the molecular mimicry phenomenon (i.e. cross-reaction of antigens of microorganisms with the own antigens of immunized individuals), and individual genetic susceptibility, but the influence of environmental factors (infections, exposure to tobacco smoke, chemicals, external pollution) may also be relevant. In that context, currently attention is also paid to the sick building syndrome (SBS) [43], which is associated with chemical agents, of natural and chemical origin, present in the environment (building), as well as with external pollution and the emergence of autoimmune/inflammatory diseases after the use of various substances for cosmetic purposes (mineral oils, guaiacol).

The differences in the vaccinated population should also be considered. For instance, a group which is subject to extensive vaccination comprises children, who are in their early life vaccinated frequently and thus in a relatively short period of time are intensively exposed to adjuvants such as Al. Nonetheless, children's environmental exposure to Al is shorter, and therefore less intense, than in adults, and also children have far fewer occasions than adults to be exposed to infectious agents. Finally, the onset of overt disease may require several years; therefore, we should expect fewer diagnoses of ASIA syndrome in this population. Children have a less mature nervous system that is more susceptible to toxic agents as well as immature renal toxin utilization, and they are more likely to have a direct toxic effect of drugs, chemical substances and, to some extent, adjuvants. The distinctness of the immature immune system has also to be taken into account, especially until 6 months of age. The second group consists of adults with all the history of previous infections, longer time of environmental exposure to toxic agents and adjuvants, and more diverse - yet less frequent - vaccination history. Military personnel can be considered as a separate group as its members receive in a specified period of time numerous vaccines prior to the planned overseas military missions. Also children and adults with already defined autoimmune diseases and immune disorders should be considered separately. This diversity of analyzed subjects may hamper comparative analysis [44].

To summarize the definition of ASIA syndrome and the establishment of its criteria enables merging on a common ground autoimmune phenomena associated with the use of adjuvants, despite diverse symptoms presented in the course of these illnesses. Current knowledge of the four related earlier defined diseases (GWS, MMF, post-vaccination phenomena, siliconosis) sheds new light on innate and acquired immunity.

Maria Maślińska and Carlo Perricone declare no conflict of interest, but Prof. Yehuda Shoenfeld appears in court in support of subjects afflicted by vaccines and silicone implants.

\section{References}

1. Clinical Immunology: principles and practice. Rich RR et al. (eds.). 3rd ed. Mosby-Elsevier, Philadelphia 2008.

2. Grzesiowski P, Hryniewicz W. Immunologia szczepień ochronnych. W: Immunologia. Gołąb J, Jakóbisiak M, Lasek W (red.). PWN, Warszawa 2004; 362-364.

3. Hogenesch $\mathrm{H}$. Mechanism of immunopotentiation and safety of Al adjuvants. Front Immunol 2012; 3: 406.

4. O'Hogan DT. New Generation Vaccine Adjuvants Encyclopedia of Life Sciences. John Wiley \& Sons 2007.

5. Israeli E, Agmon-Levin N, Blank M, Shoenfeld Y. Adjuvants and autoimmunity. Lupus 2009; 18: 1217-1225.

6. Shakya AK, Nandakumar KS. Applications of polymeric adjuwants in studying autoimmune responses and vaccination against infectious diseases. J R Soc Interface 2013; 10: 20120536.

7. Shoenfeld Y, Agmon-Levin N. 'ASIA' - autoimmune/inflammatory syndrome induced by adjuvants. J Autoimmun 2011; 36: 4-8. 
8. Israeli E. Gulf War syndrome as a part of the autoimmune (autoinflammatory) syndrome induced by adjuvant (ASIA). Lupus 2012; 21: 190-194.

9. Goldblum RM, Pelley RP, O'Donell AA, et al. Antibodies to silicone elastomers and reactions to ventriculoperitoneal shunts. Lancet 1992; 340: 510-513.

10. Evans D, Cauchemez S, Hayden FG. "Prepandemic" immunization for novel influenza viruses, "swine flu" vaccine, GuillainBarré syndrome, and the detection of rare severe adverse events. J Infect Dis 2009; 200: 321-328.

11. Agmon-Levin N, Paz Z, Israeli E, Shoenfeld Y. Vaccines and autoimmunity. Nat Rev Rheumatol 2009; 5: 648-652.

12. Hogenesch H, Azcona-Olivera J, Scott-Moncrieff C, et al. Vaccineinduced autoimmunity in the dog. Adv Vet Med 1999; 41: 733-747.

13. Koppang EO, Bjerk?s I, Haugarvoll E, et al. Vaccination-induced systemic autoimmunity in farmed Atlantic salmon. J Immunol 2008; 181: 4807-4811.

14. Satoh M, Reeves WH. Induction of lupus-associated autoantibodies in BALB/c mice by intraperitoneal injection of pristane. J Exp Med 1994; 180: 2341-2346.

15. Zafrir Y, Agmon-Levin N, Paz Z, et al. Autoimmunity following hepatitis B vaccine as part of the spectrum of 'Autoimmune (Autoinflammatory) Syndrome induced by Adjuvants' (ASIA): analysis of 93 cases. Lupus 2012; 21: 146-152.

16. Soriano A, Verrecchia E, Marinaro A, et al. Giant cell arteritis and polymyalgia rheumatica after influenza vaccination: report of 10 cases and review of the literature. Lupus 2012; 21: 153-157.

17. Lerner A. Al as an adjuvant in Crohn's disease induction. Lupus 2012; 21: 231-238.

18. Rinaldi M, Perricone R, Blank M, et al. Anti-Saccharomyces cerevisiae autoantibodies in autoimmune diseases: from bread baking to autoimmunity. Clin Rev Allergy Immunol 2013; 45: 152-161.

19. Staines DR. Do cytosine guanine dinucleotide (CpG) fragments induce vasoactive neuropeptide meduiated fatigue related autoimmune disorders? Med Hypotheses 2005; 65: 370-373.

20. Nancy AL, Shoenfeld Y. Chronic fatigue syndrome with auto-antibodies - the result of an augmented adjuvant effect of hepatitis-B vaccine and silicone implant. Autoimmun Rev 2008; 8: 52-55.

21. Vista ES, Crowe SR, Thompson LF, et al. Influenza vaccination can induce new-onset anticardiolipins but not $\beta 2$-glycoprotein-I antibodies among patients with systemic lupus erythematosus. Lupus 2012; 21: 168-174.

22. Tarján P, Sipka S, Lakos G, et al. Influenza vaccination and the production of anti-phospholipid antibodies in patients with systemic lupus erythematosus. Scand J Rheumatol 2006; 35: 241-243.

23. Katzav A, Kivity S, Blank M, et al. Adjuvant immunization induces high levels of pathogenic antiphospholipid antibodies in genetically prone mice: another facet of the ASIA syndrome. Lupus 2012; 21: 210-216.

24. Soldevilla HF, Briones SF, Navarra SV. Systemic lupus erythematosus following HPV immunization or infection? Lupus 2012; 21: 158-161.

25. Gatto M, Agmon-Levin N, Soriano A, et al. Human papillomavirus vaccine and systemic lupus erythematosus. Clin Rheumatol 2013; 32: 1301-1307.
26. Gulf War Illness and the Health of Gulf War Veterans: Scientific Findings and Recommendations. Binns JH (Committee Chair). U.S. Government Printing Office, Washington, D.C. 2008.

27. Committee on Gulf War and Health: Health Effects of Serving in the Gulf War, Update 2009 Board on the Health of Select Populations. Institute of Medicine of the National Academie the National Academies Press. Washington, D.C.

28. Petrik MS, Wong MC, Tabata RC, et al. Al adjuvant linked to Gulf War illness induces motor neuron death in mice. Neuromolecular Med 2007; 9: 83-100.

29. Gherardi RK, Coquet $M$, Chérin P, et al. Macrophagic myofasciitis: an emerging entity. Groupe d'Etudes et Recherche sur les Maladies Musculaires Acquises et Dysimmunitaires (GERMMAD) de l'Association Française contre les Myopathies (AFM). Lancet 1998; 352: 347-352.

30. Gherardi RK, Authier FJ. Macrophagic myofasciitis: characterization and pathophysiology. Lupus 2012; 21: 184-189.

31. Maubec E, Pinquier L, Viguier $M$, et al. Vaccination-induced cutaneous pseudolymphoma. J Am Acad Dermatol 2005; 52: 623-629.

32. Chérin P, Authier FJ, Gherardi RK, et al. Gallium-67 scintigraphy in macrophagic myofasciitis. Arthritis Rheum 2000; 43: 1520-1526.

33. Shoenfeld Y. Video Q\&A What is ASIA? An interview with Yehuda Shoenfeld. BMC Med 2013; 11: 118.

34. Arepalli SR, Bezabeh S, Brown SL. Allergic reactions to platinum in silicone breast implants. J Long Term Eff Med Implants 2002; 12: 299-306.

35. Lykissa ED, Maharaj SV. Total platinum concentration and platinum oxidation states in body Fluids, Tissue, and Explants from Women Exposed to Silicone and Saline Breast Implants by ICICPMS. Analytical Chemistry 2006; 78: 2925-2933.

36. Hennekens $\mathrm{CH}$, Lee IM, Cook NR, et al. Self-reported breast implants and connective-tissue diseases in female health professionals. A retrospective cohort study. JAMA 1996; 275: 616-621.

37. Janowsky EC, Kupper LL, Hulka BS. Meta-analyses of the relation between silicone breast implants and the risk of connective-tissue diseases. N Engl J Med 2000; 342: 781-790.

38. Jara LJ, Medina G, Gómez-Bañuelos E, et al. Still's disease, lupuslike syndrome, and silicone breast implants. A case of 'ASIA' (Shoenfeld's syndrome). Lupus 2012; 21: 140-145.

39. Kivity S, Katz M, Langevitz $P$, et al. Autoimmune syndrome induced by adjuvants (ASIA) in the Middle East: morphea following silicone implantation. Lupus 2012; 21: 136-139.

40. Lidar M, Agmon-Levin N, Langevitz P, Shoenfeld Y. Silicone and scleroderma revisited. Lupus 2012; 21: 121-127.

41. Vera-Lastra O, Medina G, Cruz-Dominguez Mdel P, et al. Human adjuvant disease induced by foreign substances: a new model of ASIA (Shoenfeld's syndrome). Lupus 2012; 21: 128-135.

42. Agmon-Levin N, Kivity S, Szyper-Kravitz M, Shoenfeld Y. Transverse myelitis and vaccines: a multi-analysis. Lupus 2009; 18: 1198-1204

43. Israeli E, Pardo A. The sick building syndrome as a part of the autoimmune (auto-inflammatory) syndrome induced by adjuvants. Mod Rheumatol 2011; 21: 235-239.

44. Tomljenovic L, Shaw CA. Mechanisms of Al adjuvant toxicity and autoimmunity in pediatric populations. Lupus 2012; 21: 223-230. 